\title{
EFFECT OF GESTATIONAL AGE ON GENTAMICIN PHARMACOKINETIC PARAMETERS IN THE NEWBORN
}

\author{
O. Farizaturradiah'* , Z. Mohamed', S.M.Sim', C.T. Lim² \\ Departments of 'Pharmacology and 'Pediatrics Faculty of Medicine, University of Maloya 50603 Kuala Lumpur
}

\begin{abstract}
This study investigates the pharmacokinetics of gentamicin in newborns in the Special Care Nursery in University Hospital. They were divided into 3 groups according to gestational age: Group I, 26 to 30 weeks ( $n=10)$, Group II, 31 to 35 weeks $(\mathrm{n}=27)$, and Group III, 36 to 40 weeks ( $\mathrm{n}=36)$. Each subject received $2.5 \mathrm{mg} / \mathrm{kg}$ gentamicin (gentamicin sulphate, David Bull) every $12 \mathrm{~h}$ initially. The pharmacokinetic parameters for each newborn were derived from the measured plasma $\mathrm{C}_{\max }$ and $\mathrm{C}_{\min }$ levels taken at steady state, according to the Sawchuk-Zaske method. The subsequent dosage regimen was calculated using these parameters.

Gentamicin trough levels in the newborn ranged from 0.57 to $4.94 \mu \mathrm{g} / \mathrm{mL}$ while the peak levels ranged from 4.24 to $12.42 \mu \mathrm{g} / \mathrm{mL}$. The apparent volume of distribution $\left(\mathrm{V}_{\mathrm{d}}\right)$ (means $\pm S E M$ ) increased with gestational age, the $V_{d}$ being $0.81 \pm 0.09,1.00 \pm 0.06$ and $1.49 \pm 0.06 \mathrm{~L}$ for groups I, II and III respectively. The differences between the groups were significant $(P<0.01$; Student's t-test).

There was an observable decrease in $t_{1 / 2}$ with increasing gestational age, the $t_{1 / 2}$ (mean \pm SEM) being $10.02 \pm 1.19 h, 8.53 \pm 0.38 \mathrm{~h}$ and $7.10 \pm 0.31 \mathrm{~h}$ for Groups I, II and III respectively. This decrease in the $t_{1 / 2}$ was accompanied by a similar increase in CL $(0.07$ $\pm 0.02,0.09 \pm 0.01$ and $0.15 \pm 0.01 \mathrm{l} / \mathrm{h}$ for Groups I, II and III respectively). The changes in $t_{1,2}$ and $C L$ were significant $(P<0.01)$ between Groups I and III, and between Groups II and III.

These findings show that differences exist in the pharmacokinetic parameters of newborns when grouped according to gestational age. For the effective monitoring of gentamicin especially with regard to the initial estimation of drug dosage, the appropriate set of pharmacokinetic parameters should be used for the newborn of that gestational age. (JUMMEC 1997 2(1): 35-38)
\end{abstract}

KEYWORDS: gentamicin in neonate, gentamicin pharmacokinetic, drug monitoring in neonates

\section{Introduction}

Aminoglycosides are a cornerstone in the therapy of severe gram-negative infections, despite their potential toxicity. Nephrotoxicity and ototoxicity are important adverse effects clinically, and hence form the basis for attempts to rationalise therapy (1). The main aminoglycoside used in the Special Care Nursery (SCN) Ward of the University Hospital, Kuala Lumpur, is gentamicin.

Peak serum concentration of $4 \mu \mathrm{g} / \mathrm{ml}$ has been sug. gested as the minimal inhibitory concentration of gentamicin for most susceptible gram-negative organisms (2). While a peak serum concentration of 4 to $8 \mu \mathrm{g} / \mathrm{ml}$ is considered to be in the therapeutic range, a concentration of more than $10 \mu g / \mathrm{ml}$ is considered toxic ( 3 ). It has been recommended that the trough serum concentration be maintained at less than $2 \mathrm{\mu g} / \mathrm{m} /$ to prevent toxic effects (2). Therefore, serum gentamicin concentrations should be monitored and the dose adjusted to maintain the levels within the therapeutic range.

The fear of the ototoxic and nephrotoxic effects described in adults has led several authors to recommend monitoring of plasma levels of gentamicin in neonates (4-6). The current recommended dose regimen of gentamicin in the newborn is $2.5 \mathrm{mg} / \mathrm{kg}$ every $12 \mathrm{~h}$ in the first week of life and $2.5 \mathrm{mg} / \mathrm{kg}$ every $8 \mathrm{~h}$ in the second week (7). This regimen has been established in order to obtain appropriate gentamicin serum concentrations. In spite of this, the risk of toxicity or therapeutic failure is high (8) because there is a large inter-patient variabil-

Corresponding address:

Associate Protessor Zahurin Mohamed

Depi of Pharmacology, Faculty of Medicine, University of Malaya,

50603 Kuala Lumpur, Malaysia. 
ity in the pharmacokinetic parameters of gentamicin depending on the stage of maturity of the newborn (9).

The aim of this study was to investigate the pharmacokinetics of gentamicin in the newborn, grouped according to gestational age.

\section{Method}

\section{Patients}

The study subjects consisted of newborns admitted to the Special Care Nursery (SCN), University Hospital, Kuala Lumpur. They received an initial bolus parenteral gentamicin (manufactured by David Bull; marketed as gentamicin sulphate) at $2.5 \mathrm{mg} / \mathrm{kg} / 12 \mathrm{~h}$ for 2 days. They were divided into 3 groups according to gestational age: Group a comprising newborns of gestational age from 26 to 30 weeks ( $n=\mid 0)$, Group $|1,3|$ to 35 weeks $(n=27)$, and Group III, 36 to 40 weeks ( $n=36$ ).

\section{Dosage Regimens and Blood Sampling}

All patients were on a fixed regimen of gentamicin therapy $(2.5 \mathrm{mg} / \mathrm{kg} / / 2 \mathrm{~h}, \mathrm{~V} / \mathrm{M})$ for at least 2 days before this study, and were therefore considered to be at steady state. Trough serum samples were collected just before and peak serum sample at $0.5-1.0 \mathrm{~h}$ after gentamicin administration.

\section{Assay}

Gentamicin serum concentrations were determined by immunofluorescent polarization assay (TDx,Abbott).

\section{Calculation of Various Pharmacokinetic Parameters}

The pharmacokinetic parameters for the individual newborn were derived from the measured peak and trough levels according to the Sawchuk-Zaske method (II). The subsequent dosage regtmens were calculated using these parameters.

\section{Statistical Analysis}

Data are presented as mean \pm SEM of $n$ determinations. The statistical significance of the difference between two means was calculated using student's t-test for unpaired samples.

\section{Results}

The measured gentamicin trough levels in the newborn ranged from 0.57 to $4.94 \mu \mathrm{g} / \mathrm{mL}$. There was a significant difference in the mean trough levels between Groups I and III $(P<0.05$ ), and between Groups II and III $(P<0.01)$, but not between Groups I and II (Figure I). The measured peak levels ranged from 4.24 to 12.42 $\mu \mathrm{g} / \mathrm{ml}$, but the mean levels were not significantly differ- ent between the three groups (Figure 2).

The apparent volume of distribution $\left(V_{d}\right)$ increased with gestational age, the $V_{d}$ being $0.81 \pm 0.09,1.00 \pm 0.06$ and $1.49 \pm 0.06 \mathrm{~L}$ for Groups I, II and III respectively. The differences between the groups were significant $(P<0.05$, Figure 5).

Despite the increase in the $V_{d}$, there was an observable decrease in $\mathrm{t}_{1 / 2}$ with increasing gestational age, the $\mathrm{t}_{1 / 2}$ being $10.02 \pm 1.19 h, 8.53 \pm 0.38 \mathrm{~h}$ and $7.10 \pm 0.31 \mathrm{~h}$ for groups 1 , 11 and 111 . This decrease in the $t_{1 / 2}$ was accompanied by an increase in CL $(0.07 \pm 0.02,0.09 \pm 0.01$ and $0.15 \pm 0.01 \mathrm{~L} / \mathrm{h}$ for Groups I, II and III respectively). The changes in $t_{1 / 2}$ and $C L$ (Figures $3 \& 6$ ) were significant between Groups I and III ( $P<0.02)$, and between Groups II and III $(P<0.01)$. No significant difference was found between groups I and II (Figures $3 \& 6$ ).

The subsequent recommended dosage regimen in the form of calculated dose and dosing interval, for each group of newborns, is shown in Table l. Based on the pharmacokinetic parameters obtained for each individual newborn, a new dosage regimen (dose and dosing interval) was recommended so as to achieve the desired peak and trough gentamicin levels in these newborns. There were no significant differences in the mean calculated dose among the three groups (Table 1). There were, however, significant differences in the mean dosing intervals between Groups I and III ( $P<0.02)$, and Groups $\mid I$ and III $(P<0.01)$, but not between Groups I and II.

\section{Discussion}

The measured gentamictn peak levels were within the therapeutic range in all the three groups. However, the measured gentamicin trough levels were found to be higher than $2 \mu \mathrm{g} / \mathrm{mL}$, especially in Groups I and II (Figure 1), hence necessitating an adjustment of dosage regimen. This finding is consistent with studies done by Garcia-Delgado et al. (32) where the initial dosages of $2.45 \pm 0.4 \mathrm{mg} / \mathrm{kg}$ were sufficient to attain potentially therapeutic blood levels. These authors suggested that the dose should be administered at different intervals according to gestational age in order to allow the trough levels to come down to values which are considered to be therapeutic.

The measured gentamicin trough levels were found to decrease with increasing gestational age but the measured peak levels were not significantly different (Figures I \& 2). This decrease in trough levels was a conse. quence of a decrease in the elimination half-life with: increasing gestational age (Figure 3 ). The elimination half-life of a drug is a function of its volume of distribution and clearance. In this study, the volume of distribution was found to increase with gestational age (Figure 5), but this increase was mainly due to an increase 
Table I. Subsequent recommended dose and dosing intervals for the newborns grouped according to gestational age presented as means \pm SEM of $n$ determinations.

\begin{tabular}{llll}
\hline Group & I & II & III \\
\hline Age (weeks) & $26-30$ & $31-35$ & $36-40$ \\
Number of patients $(\mathrm{n})$ & 10 & 27 & 36 \\
Dose Calculated $(\mathrm{mg} / \mathrm{kg})$ & $3.77 \pm 0.24$ & $3.74 \pm 0.15$ & $3.49 \pm 0.14$ \\
range & $(2.49-4.93)$ & $(2.31-5.53)$ & $(1.89-6.17)$ \\
Dosing Intervals $(\mathrm{h})$ & $24.22 \pm 2.87$ & $20.61 \pm 0.92$ & $17.15 \pm 0.75$ \\
range & $(11.16-43.14)$ & $(9.23-29.85)$ & $(9.10-28.57)$ \\
\hline
\end{tabular}

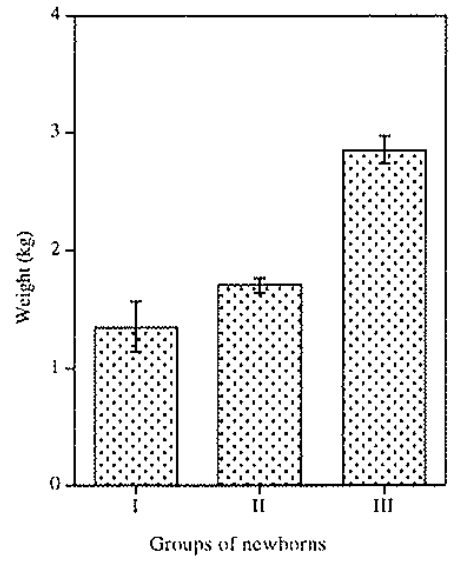

Figure I. Gentamicin trough levels in groups of newborns, divided according to gestational age. $P<0.05$ for Group I versus III; $\mathrm{P}<0.01$ in Group II versus III.

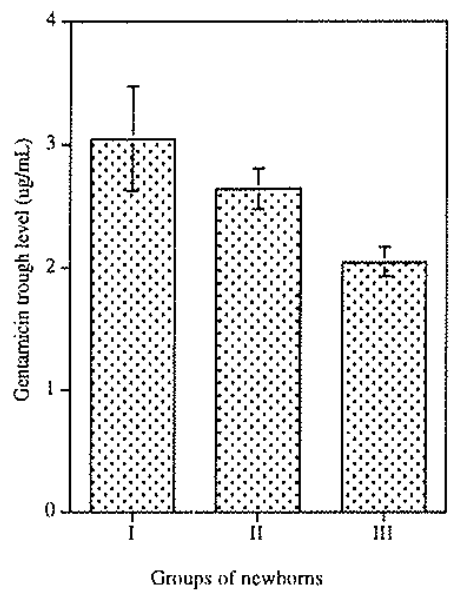

Figure 4. Patients' weight in groups of newborns, divided according to gestational age. $P<0.01$ for Group I versus II; $P<0.01$ for Group I versus III; $P<0.01$ for Group II versus III.

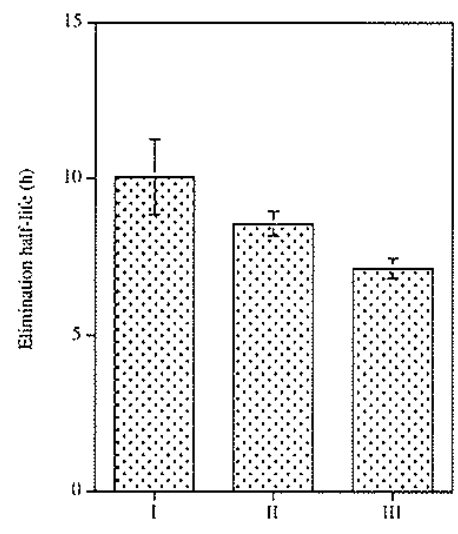

Grapus of newborms

Figure 2. Gentamicin peak levels in groups of newborns, divided according to gestational age.

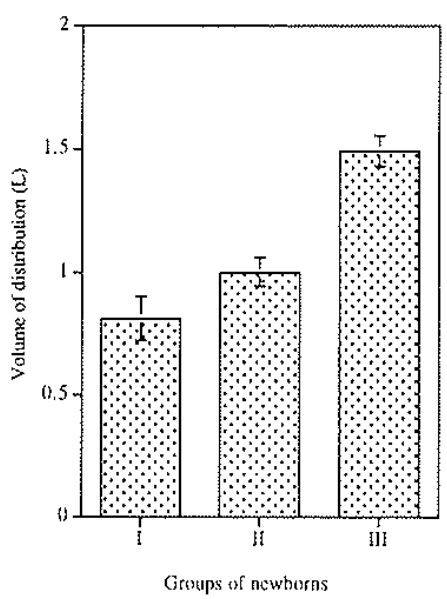

Figure 5. Gentamicin volume of distribution $\left(V_{d}\right)$ in groups of newborns, divided according to gestational age. $P<0.05$ for Group 1 versus II; $P<0.01$ for Group I versus III; $P<0.01$ for Group II versus III.

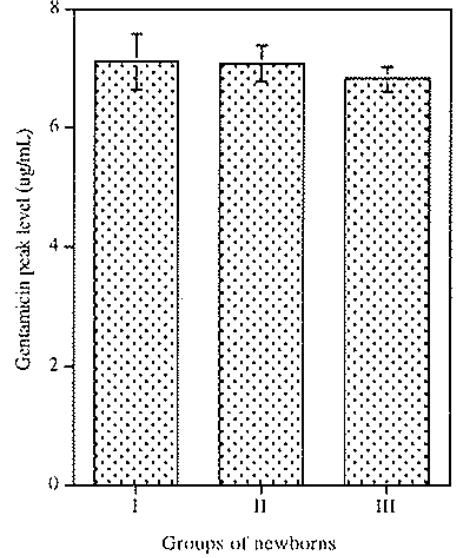

Figure 3. Gentamicin elimination half-life $\left(t_{1 / 2}\right)$ in groups of newborns, divided according to gestational age. $P<0.02$ for Group I versus III; $P<0,0$ l for Group II versus III.

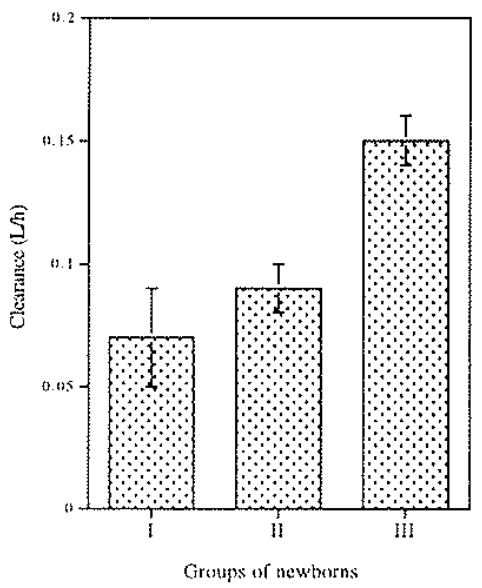

Figure 6. Gentamicin clearance (CL) in groups of newborns, divided according to gestational age. $P<0.01$ for Group I versus III; $P<0.01$ for Group II versus III 
in body weight of the neonates (Figure 4). Therefore, the observed decrease in the gentamicin trough levels with increasing gestational age was not likely to be due to a change in the volume of distribution, but rather to a change the clearance.

Our study showed that the decrease in the elimination half-life with increase in gestational age(Figure 3) was accompanied by a corresponding increase in plasma clearance (Figure 6). This finding is consistent with work done by Semchuk et ol. (13), where younger newborns demonstrated slower elimination half-lives than did older newborns. The decrease in elimination half-life is likely to be due to an increased ability of the eliminating organs to clear the drug with increasing gestational age.

Substantial changes in physiologic parameters occur in neonates, especially in the premature newborn (14). Cardiac output, renal blood flow, glomerular filtration rate, and extracellular fluid are physiologic parameters that affect gentamicin volume of distribution, elimination halfulife and clearance. Although in this study it was clear that the decrease observed in the gentamicin trough levels was likely to be due to the significant decrease observed in the elimination half-life, the fact that the pharmacokinetic parameters can vary substantially from day to day due to changes in physiologic functions should be taken into consideration.

In our study, in order to achieve peak serum gentamicin concentrations of $8 \mu \mathrm{g} / \mathrm{ml}$ and trough concentrations of less than $2 \mu \mathrm{g} / \mathrm{m}$ l, younger newborns (26-30 weeks gestational age) require a larger dose ( $3.77 \mathrm{mg} / \mathrm{kg}$ ) with a longer dosing interval $(24.22 \mathrm{~h}$ ). Semchuk et ol. (13) suggested that younger newborns (less than 34 weeks gestational age) would be likely to require $4 \mathrm{mg} / \mathrm{kg}$ as an initial dose in order to achieve peak serum gentamicin concentrations of 8 $\mu \mathrm{g} / \mathrm{ml}$. Work done by Lopez-Samblas et al. (15) found that dosing protocol based on gestational age was reproducible and reliable in achieving therapeutic gentamicin serum concentration in neonates. In their study, newborns of gestational age less than 30 weeks were given $3.0 \mathrm{mg} / \mathrm{kg} / 24 \mathrm{~h}$ and those of gestational age $30-37$ weeks were given $2.5 \mathrm{mg} / \mathrm{kg} / \mathrm{l} 8 \mathrm{~h} / \mathrm{V}$.

\section{Conclusion}

Our findings show that there are differences in the pharmacokinetic parameters of the different groups of newborn grouped according to gestational age. The data show that the gentamicin dose regimen recommended in the literature for newborn infants within the first week of life $(2.5 \mathrm{mg} / \mathrm{kg}$ every $12 \mathrm{~h})$ may be more than is necessary. These differences should be taken into consideration for the effective monitoring of gentamicin especially with regard to the initial estimation of drug dosage.

\section{References}

1. Barclay ML and Begg El. Aminoglycoside toxicity and relation to dose regimen. Adverse Drug React Toxicol Rev 1994; 13(4): 207-34.

2. Hindmarsh KW, Nation RL, Williams $G L$, John $E$ and French JN. Pharmacokinetics of gentamicin in very low birth weight preterm infants. Eur $1 \mathrm{Clin}$ Pharmacol 1983 ; 24:649-53.

3. DitoWR. Therapelitic drug monitoring : aminoglycoside antibiotics. Diafn Med. 1980; 3: 77-85.

4. Anderson JB, Rosdahl $N$ and Vejlsgaard R. Aspects of pharmacology of gentamicin in newborn infants. Acta Paediat Scan 1972;61; 343-9.

5. Assael BM, Clansu V, Marini A, Penett $P$ and Serini F. Gen. tamicin dosage in preterm and term neonates. Arch Dis Child 1977; 52(1): 883-6.

6. Taytor M and Keane $C$. Gentamicin dosage in children. Arch Dis Chited 1976; 51: 369-72.

7. Mc Cracken GH and Nelson L. Aminoglycosides. In: McCracken GH. Nelson L. Eds. Antimicrobial therapy for newborns. New York: Grune \& Stratton, Inc.; 1983; 44-65.

8. Mulhall A, De Louvois J and Hurley R. Incidence of potentially toxic concentrations of gentamicin in the neonates. Arch Dis Child 1983; 58:897-900.

9. Pons G. d'Athis P, Rey E, Lauture de, Richard MO, Badoua J. and Olive $G$. Gentamicin monitoring in neonates, Ther Drug Monit 1988; 10: 421-27.

10. Faura CC. Garcia MR and Horga JF. Monitoring serum levels of gentamicin to develop a new regimen for gentamicin dosage in newborns. Ther Drug Monit 1991:13: 268-76.

11. Sawchuk $R$ and Zaske D. Pharmacokinetics of dasing regimens which utilize multiple intravenous infusions: gentamicin in burn patients. J. Pharmacokinet Biopharm 1976; 4: 183-95

12. Garcia-Delgado R, Sanchez-Romero A, Tebar-Gil R and Marco-Macian A. Monitoring of gentamicin serum concentration in neonates. Usefulness in adjustment of dosage. An Esp Pediatr 1997; 46(1):47-52.

13. SemchukW, Borgmann J and Bowman L. Determination of a gentamicin loading dose in neonates and infants. Ther Drug Monit 1993; 15(1): 47-51.

14. Zaske DE, Shikuma LR and Tholl LR. Aminoglycosides: In: Taylor W], Diers Caviness MH, Eds. A textbook for the clinical application of therapeutic drug monitoring. Irving TX:Abbot Laboratories; 1986; 285-320

15. Lopez-Samblas AM, Torres $C L$, Wang $H$, Feuer WJ and Goldberg RN. Effectiveness of a gentamicin dosing protocol based on postconceptional age: comparison to pubIsshed neonatal guidelines. Ann Pharmacother 1992;26(4): 534-8. 